\title{
Coronary microvascular disease: diagnostic evaluation
}

\author{
Dinesh Voruganti, Jawahar L. Mehta \\ Division of Cardiology, University of Arkansas for Medical Sciences, Little Rock, Arkansas 72205, USA.
}

Correspondence to: Dinesh Voruganti, MD, MS, Division of Cardiology, University of Arkansas for Medical Sciences, 4301 W Markham St, Slot 549, Little Rock, Arkansas 72205, USA. E-mail: dcvoruganti@uams.edu

How to cite this article: Voruganti D, Mehta JL. Coronary microvascular disease: diagnostic evaluation. Vessel Plus 2021;5:55. https://dx.doi.org/10.20517/2574-1209.2021.60

Received: 6 Apr 2021 First Decision: 5 Jul 2021 Revised: 21 Jul 2021 Accepted: 18 Aug 2021 Published: 5 Nov 2021

Academic Editors: Gaetano Antonio Lanza, Alexander D. Verin Copy Editor: Yue-Yue Zhang Production Editor: Yue-Yue Zhang

\begin{abstract}
The diagnosis of coronary microvascular disease (CMD) is vital in a subset of patients with symptoms of myocardial ischemia. The typical ischemic findings on resting electrocardiogram and echocardiogram are uncommon or absent in CMD. Therefore, a high clinical suspicion is essential. We aim to review the invasive and non-invasive diagnostic testing for CMD. The goal is to assess the endothelial dysfunction related to vasoconstriction or reduced coronary blood flow reserve. Non-invasive testing includes resting electrocardiogram, exercise electrocardiogram, transthoracic color Doppler echocardiography, myocardial contrast echocardiography, positron emission tomography, and cardiac magnetic resonance imaging. Comprehensive invasive assessment includes coronary angiography followed by fractional functional flow reserve assessment, coronary flow reserve testing with intravenous acetylcholine with or without intravenous adenosine.
\end{abstract}

Keywords: Coronary microvascular dysfunction, intracoronary acetylcholine, intracoronary adenosine, coronary flow velocity, coronary flow reserve, myocardial contrast echocardiography, positron emission tomography, cardiac magnetic resonance

\section{INTRODUCTION}

Coronary microvascular disease (CMD) is a structural and functional abnormality in the coronary microvasculature. CMD is usually secondary to vasospasm and endothelial dysfunction. However, there is accumulating evidence suggesting inflammation is playing an essential role ${ }^{[1-3]}$. CMD is more common in 
females ${ }^{[4]}$. A high index of clinical suspicion is necessary because CMD is associated with increased morbidity and mortality ${ }^{[5]}$. The evidence of ischemic signs of CMD on a resting electrocardiogram (ECG) and resting transthoracic echocardiography (TTE) are usually not present or may be absent. Direct visualization of coronary microvasculature is beyond the resolution of conventional imaging such as fluoroscopy, echocardiography, or computed tomography. Hence, the assessment of CMD depends on techniques to interrogating the physiology of the coronary microvasculature. Among patients with nonobstructive coronary artery disease, the diagnostic evaluation of CMD is considered while ruling out other causes, which include myocardial infarction with normal coronary arteries such as Takotsubo cardiomyopathy, spontaneous coronary artery dissection, myocarditis, and coronary artery embolism. The underlying hypothesis in diagnosing CMD is to evaluate reduced coronary vasodilatation or increased coronary vasoconstriction by measuring coronary flow reserve (CFR)/coronary flow velocity (CFV). This review discusses non-invasive and invasive approaches used to diagnose CMD (summarized in Table 1).

\section{NON-INVASIVE TESTING}

\section{Resting electrocardiogram}

The resting ECG is universally available and an inexpensive test to evaluate myocardial ischemia. The resting ECG is usually normal in most patients with CMD. Therefore, ECG has poor sensitivity to establish the diagnosis of CMD. The absence of ECG changes does not exclude the diagnosis. If CMD is suspected, further workup must be pursued, as elaborated below.

\section{Exercise electrocardiogram}

Exercise ECG is a highly specific test and is an excellent test to evaluate coronary ischemia. Exercise ECG is performed by measuring ECG at rest followed by exercise (treadmill or bike). It is cheap, widely available with good reproducibility. It also provides prognostic information based on the duration of exercise, symptoms, and ECG changes. However, it is limited by its inability to provide hemodynamics in the coronary vasculature. Therefore, an exercise ECG could be a good screening tool supplemented by other diagnostic modalities. Figure 1 shows typical ECG changes suggestive of myocardial ischemia in a patient with normal coronary arteriograms. Among 33 patients with angina of unknown cause, Chen et al. ${ }^{[7]}$ demonstrated ischemia-related changes in 17 patients during a treadmill exercise test. Compared to patients who did not have symptoms on treadmill exercise test, patients with symptoms on had a significantly lower maximum great cardiac vein flow $(108.8 \pm 47.0$ vs. $146.4 \pm 23.4 \mathrm{~mL} / \mathrm{min}, P=0.007)$, higher minimum coronary vascular resistance $(0.94 \pm 0.41 v s .0 .61 \pm 0.09 \mathrm{mmHg} / \mathrm{mL} / \mathrm{min}, P=0.003)$, and lower corrected great cardiac vein flow reserve (great cardiac vein flow/rate-pressure product, $0.0087 \pm 0.0036 v s .0 .0125 \pm$ $0.0019, P=0.001)$ after dipyridamole infusion $(0.56 \mathrm{mg} / \mathrm{kg}$ for $4 \mathrm{~min})$. Chen et al.$^{[7]}$ concluded that CMD was likely related to effort-related angina and ischemic ECG changes during treadmill exercise testing based on these findings.

\section{Hyperventilation and cold-pressor stress echocardiography}

Hirano et al. ${ }^{[8]}$ described the hyperventilation and cold-pressor stress echocardiography to detect CMD among 43 patients suspected to have vasospastic angina. It was performed by hyperventilation for 6 -min (30 respiration/min) and then right-hand immersion in ice water for $2 \mathrm{~min}$, based on an earlier protocol by Shimizu et al. ${ }^{[9]}$. The study demonstrated multivessel spasms in 26 patients by stress echocardiography and in 23 patients by angiography. This test's sensitivity, specificity, and diagnostic accuracy for detecting CMD were $48 \%, 100 \%$, and $60 \%$, respectively. However, with the recent advances in sensitive measurements of coronary physiology and imaging, this method is not frequently used. 
Table 1. Coronary microvascular disease non-invasive and invasive diagnostic modalities with advantages and disadvantages

\begin{tabular}{|c|c|c|}
\hline Test & Advantages & Disadvantages \\
\hline Resting electrocardiogram & $\begin{array}{l}\text { Universal availability } \\
\text { Cheap to perform }\end{array}$ & Do not provide information during the activity \\
\hline Exercise electrocardiogram & $\begin{array}{l}\text { Universal availability } \\
\text { Cheap to perform } \\
\text { Physiological test }\end{array}$ & $\begin{array}{l}\text { It does not provide information on hemodynamics in the } \\
\text { coronary vasculature }\end{array}$ \\
\hline $\begin{array}{l}\text { Hyperventilation and cold-pressor stress } \\
\text { echocardiography }\end{array}$ & $\begin{array}{l}\text { Highly specific test } \\
\text { Easy to perform } \\
\text { Cheap to perform }\end{array}$ & $\begin{array}{l}\text { Not convenient for the patient } \\
\text { Needs technical expertise }\end{array}$ \\
\hline Transthoracic Doppler echocardiography & $\begin{array}{l}\text { Universal availability } \\
\text { Cheap to perform }\end{array}$ & $\begin{array}{l}\text { Need technical expertise } \\
\text { Poor body habitus precludes accurate assessment }\end{array}$ \\
\hline Myocardial contrast echocardiography & $\begin{array}{l}\text { Universal availability } \\
\text { Cheap to perform }\end{array}$ & $\begin{array}{l}\text { Needs technical expertise } \\
\text { Cannot rule out between myocardial bridging, coronary } \\
\text { tortuosity, and CMD }\end{array}$ \\
\hline $\begin{array}{l}\text { Multislice detector computed } \\
\text { tomography }\end{array}$ & Quick to perform & $\begin{array}{l}\text { lonizing radiation } \\
\text { Limitation on accurate physiologic assessment of } \\
\text { coronary microvasculature } \\
\text { Expensive }\end{array}$ \\
\hline Cardiac magnetic resolution imaging & $\begin{array}{l}\text { High resolution } \\
\text { Non-invasive } \\
\text { No radiation exposure }\end{array}$ & $\begin{array}{l}\text { Expensive } \\
\text { Needs technical expertise } \\
\text { Risk of nephrogenic systemic fibrosis in chronic kidney } \\
\text { disease }\end{array}$ \\
\hline $\begin{array}{l}\text { Positron emission tomography perfusion } \\
\text { imaging }\end{array}$ & $\begin{array}{l}\text { Non-invasive } \\
\text { Most-validated } \\
\text { Provides prognostic data }\end{array}$ & $\begin{array}{l}\text { Expensive } \\
\text { lonizing radiation } \\
\text { Not universally available }\end{array}$ \\
\hline $\begin{array}{l}\text { Invasive coronary angiogram } \\
\text { pharmacologic testing }\end{array}$ & $\begin{array}{l}\text { Accurate assessment of coronary } \\
\text { physiology using pressure wires }\end{array}$ & $\begin{array}{l}\text { Invasive test associated with risk of ventricular } \\
\text { arrhythmias during pharmacologic testing } \\
\text { Expensive }\end{array}$ \\
\hline
\end{tabular}

A Exercise stress testing

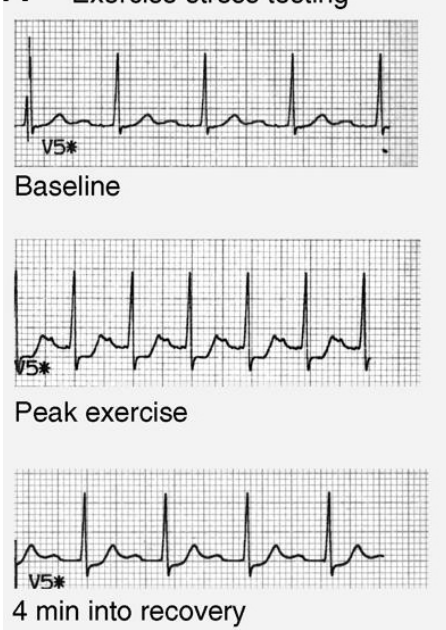

B

Continuous ambulatory ECG monitoring

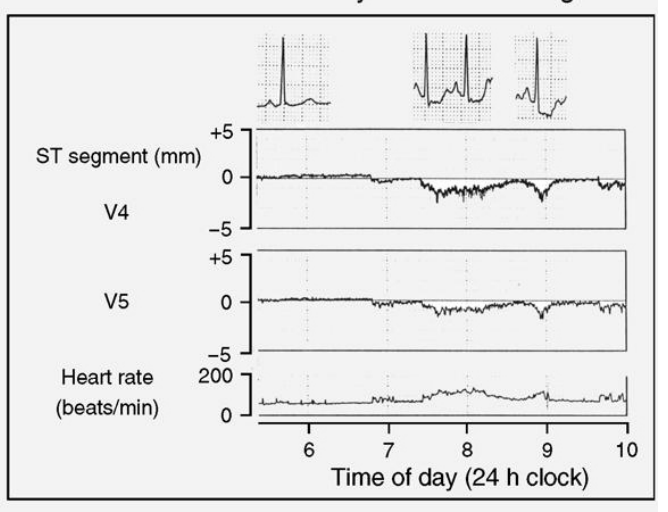

Figure 1. Electrocardiogram changes in a patient with normal coronary angiogram during exercise stress testing (A) and Holter monitor (B). Adapted from ${ }^{[6]}$.

\section{Transthoracic color Doppler echocardiography}

TTE uses ultrasonic sound waves to characterize the cardiac structures. Using the Doppler principle, TTE provides a functional assessment of the valves, blood flow, and myocardium. TTE is widely available, inexpensive, and easily performed. The echocardiographic imaging of the distal left anterior descending artery was described originally by Voci et al. ${ }^{[10]}$ in 25 out of 33 study participants (with coronary artery disease) and Hozumi et al. ${ }^{[11]}$ in 23 participants in whom CFV was measured in the distal LAD by a Doppler 
guidewire at the time of coronary angiography. The middle to the distal part of LAD was imaged by color Doppler. Once imaged, a pulse Doppler was used to measure coronary blood flow, peak and mean flow velocity, deceleration time, and deceleration rate. The authors concluded that CFV reserve from transthoracic Doppler echocardiography correlated highly with those from Doppler guide wire examinations (CFV: averaged peak velocity: $r=0.97$; averaged diastolic peak velocity: $r=0.97$; systolic peak velocities: $r=0.97$; diastolic peak velocity: $r=0.98$ ). Galiuto et al ${ }^{[12]}$ studied this phenomenon in a small cohort of patients with cardiac syndrome $\mathrm{X}$, another name for $\mathrm{CMD}$, by using intravenous administration of adenosine $(0.14 \mathrm{mg} / \mathrm{kg} / \mathrm{min}$ for $90 \mathrm{~s})$ followed by transthoracic echocardiography performed in the left lateral decubitus position at the cardiac apex to image the distal anteroseptal region; CFR was measured by Doppler echocardiography as an adenosine/rest velocity ratio and by myocardial contrast echocardiography as a microvascular volume, velocity, and flow adenosine/rest ratio. Compared with controls, patients with syndrome X demonstrated lower CFR, CFV, and microvascular flow reserves. Prognostically, the CFR by TTE has shown better outcomes among patients with normal CFR at 48 months follow-up ${ }^{[13]}$. A good correlation has been demonstrated between echocardiographic Doppler measurements and positron emission tomography. However, compared to positron emission tomography, echocardiographic Doppler imaging is limited by echocardiographic challenges in visualizing coronary arteries, technical expertise, and poor echo windows in many patients ${ }^{[1,15]}$.

\section{Myocardial contrast echocardiography}

Myocardial contrast echocardiography (MCE) involves the intravenous administration of an ultrasound contrast agent $\left[1.5 \mathrm{~mL}\right.$ of Definity ${ }^{\circ} 17$ diluted in $28.5 \mathrm{~mL}$ of saline solution $(0.09 \%)$ for a total volume of $30 \mathrm{~mL}$, as a continuous intravenous infusion at a rate of $90 \mathrm{~mL} / \mathrm{h}]^{[16]}$. This is followed by TTE with a vasodilator stress agent (e.g., dipyridamole). Assessment of wall motion during rest and infusion of vasodilator was performed by measuring mean microbubble velocity and myocardial blood volume and computing myocardial blood flow $(\mathrm{MBF})^{[16]}$. The authors found that MBF reserve was significantly reduced in patients with CMD, which can be explained either based on increased resting MBF or inability of the resistance vessels to dilate during stress or both. Even though MCE measured hemodynamics in the coronary vasculature, this study was limited by requiring high technical expertise, limiting the study to imaging only the interventricular septum and inability to differentiate low MBF due to myocardial bridging and coronary tortuosity.

\section{Multislice detector computed tomography with fractional functional flow assessment}

Multislice detector computed tomography involves the intravenous administration of iodinated contrast and adenosine $(0.14 \mathrm{mg} / \mathrm{kg} / \mathrm{min}$ for $5 \mathrm{~min})$ to image the coronary vasculature. Images are analyzed by measuring the attenuation over time in basal and hyperemic conditions and plotting time-attenuation curves. Fractional functional flow using multislice detector computed tomography has been established to evaluate epicardial coronary occlusions. However, the current imaging does not incorporate the influence of microvasculature ${ }^{[17]}$. Therefore, multislice detector computed tomography is currently not used to evaluate CMD. Micro-optical coherence tomography, a relatively new application to visualize the endothelial cells in coronary arteries, has been described by Nishimiya et al. ${ }^{[18]}$. This may help in better understanding the physiology of coronary micro-vasculature in the future.

\section{Cardiac magnetic resonance imaging}

Cardiac magnetic resonance imaging (CMRI) has emerged as a good option for the non-invasive evaluation of the heart. CMRI uses strong magnetic fields to generate images of the heart and blood vessels. CMRI is also used to evaluate cardiac hemodynamics by incorporating functional assessment techniques. In patients with $\mathrm{CMD}$, magnetic resonance imaging can determine coronary blood flow (CBF) during maximal hyperemia by administering vasodilators such as adenosine ${ }^{[19]}$. Panting et al. ${ }^{[20]}$ described subendocardial 
perfusion defects after intravenous administration of adenosine in 20 patients with cardiac syndrome X. Lanza et al. ${ }^{[21]}$ confirmed the utility of magnetic resonance imaging with a dobutamine stress test in 18 patients with syndrome $\mathrm{X}$ by showing perfusion defects in LAD artery territory. Cardiac magnetic resonance imaging has the advantages of allowing high spatial resolution, lack of ionizing radiation, functional assessment of cardiac function while allowing assessment of microvascular blood flow. Contraindications for CMRI include the risk of nephrogenic systemic fibrosis in end-stage renal disease patients, the presence of non-MRI compatible hardware in the body, and gadolinium contrast allergy. Disadvantages of CMRI also include - not being universally widely available and necessitates relevant expertise in interpreting results.

\section{Positron emission tomography-computed tomography perfusion imaging}

Positron emission tomography-computed tomography (PET-CT) is a non-invasive nuclear medicine technique involving administering a specific intravenous radio-isotopic tracer (such as ${ }^{13} \mathrm{NH}_{3}, \mathrm{H}_{2}{ }^{15} \mathrm{O}$, and ${ }^{82} \mathrm{Rb}$ ) to acquire sequential images using an $\mathrm{x}$-ray computed tomography. This enables quantifying MBF per gram of tissue uptake during the rest and stress phase (induced with a vasodilator). PET-CT allows measuring MBF globally and regionally by the quantification of the myocardial radio-isotopic tracer uptake. CFR is calculated by the ratio of MBF in the hyperemic phase with a vasodilator and at rest. Murthy et al. ${ }^{[22]}$ assessed coronary microvascular endothelium-independent dysfunction in 405 men and 813 women by positron emission tomography. CFR $<2.0$ in the absence of significant epicardial coronary artery stenosis was considered diagnostic of CMD. The role of positron emission tomography in patients with CMD and non-ischemic cardiomyopathies (such as dilated cardiomyopathy, hypertrophic cardiomyopathy, Fabry's disease, and amyloidosis) has been extensively studied to show lower CFR in these patients compared to controls $^{[19-22]}$. While PET is considered the future of nuclear cardiology, several limitations need to be acknowledged. First, PET is expensive and time-consuming. Second, it is not widely available and requires technical expertise. Third, the resolution of positron emission tomography is poor compared to CMRI. However, future studies evaluating the combined imaging using positron emission tomography with CT may improve the diagnostic capabilities.

\section{Invasive testing}

Coronary angiography is necessary for diagnosing CMD in terms of ruling out epicardial obstructive coronary artery disease (CAD). It is routinely performed in patients with angina and abnormal non-invasive cardiac stress test. In the absence of significant epicardial disease, a delayed distal vessel opacification of contrast may be noted. This is referred to as the coronary slow flow phenomenon ${ }^{[23]}$. For further evaluation, patients with non-obstructive CAD with stenosis $<80 \%$ and fractional functional flow reserve (FFR) $>0.80$ additional testings for coronary angiography are pursued. FFR is the most validated and the gold standard to identify non-obstructive stenosis. However, in recent years, non-hyperemic intracoronary pressure assessments have gained popularity. Instantaneous wave-free pressure ratio (iFR) was evaluated in the iFR SWEDHEART, and the DEFINE-FLAIR study revealed that iFR predicted outcomes like FFR. Less invasive quantitative flow ratio and diastolic hyperemia-free ratio also demonstrated good accuracy compared to $\mathrm{FFR}^{[24,25]}$. During angiography, functional testing for CMD is performed by measuring the microvascular dysfunction with intracoronary acetylcholine and non-endothelial microvascular dysfunction with adenosine ${ }^{[26]}$. Invasive provocative testing using acetylcholine has a small risk of major complications. In a review by Ciliberti et al. ${ }^{[27]}$, acetylcholine $(n=6183)$ administration was associated with a $1 \%$ risk of ventricular tachycardia/ventricular fibrillation and a $3 \%$ risk of transient bradycardia, $2 \%$ risk of paroxysmal or persistent atrial fibrillation. This small risk continues to limit the universal application of this test, at least in the United States. 


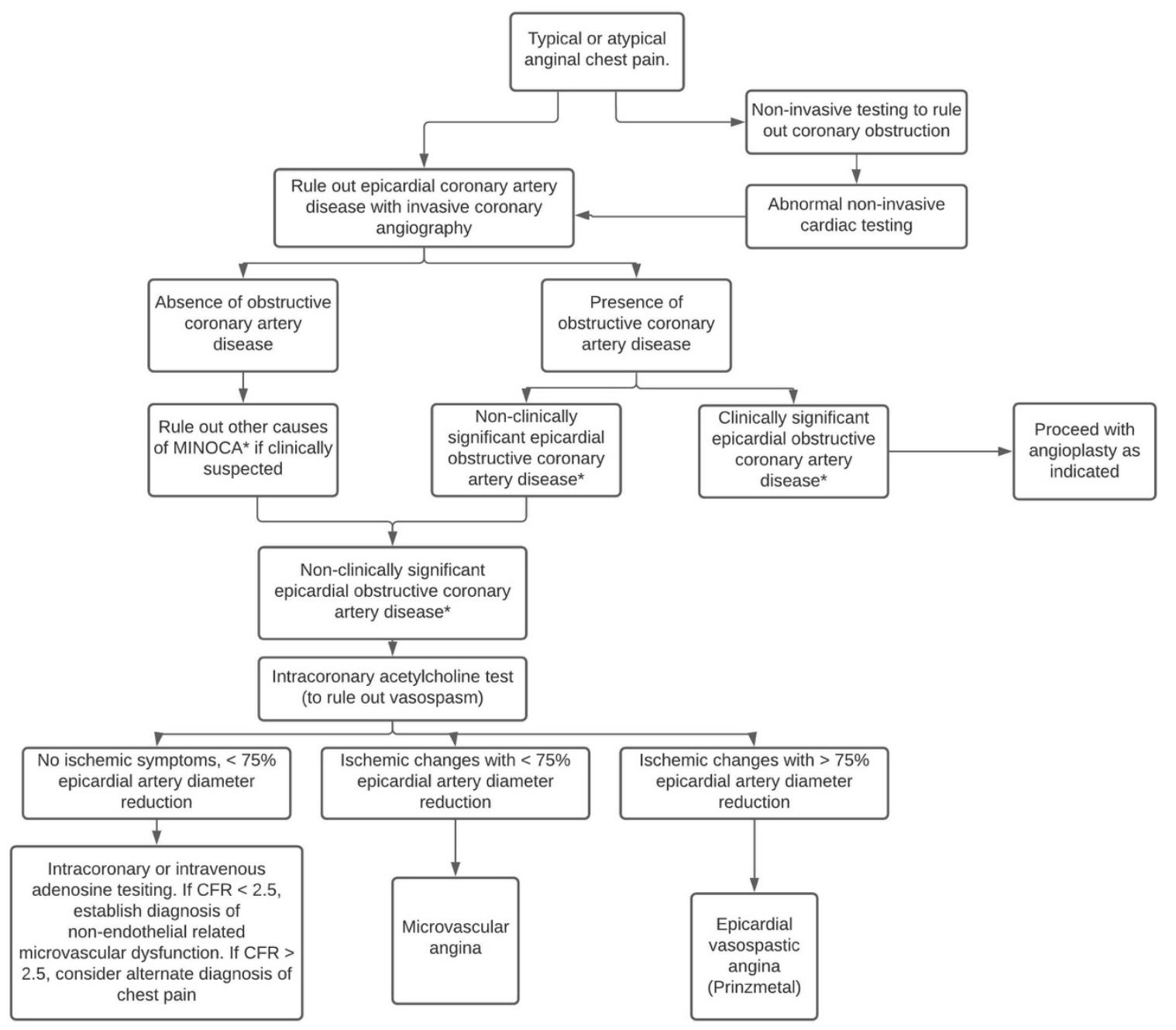

Figure 2. Flow chart for evaluation of coronary microvascular disease. It is adapted with permission from ${ }^{[3]}$.

\section{Pharmacologic coronary endothelial and non-endothelial function testing}

The pharmacologic testing for CMD involves performing a coronary angiography by administering vasodilator drugs in the coronary arteries and measuring coronary blood flow. During coronary angiography, the coronary endothelial function is assessed by injecting $50 \mu \mathrm{g}$ acetylcholine by intracoronary route over 2 to $3 \mathrm{~min}^{[26]}$. After each injection, coronary angiography is performed. Endothelial dysfunction is diagnosed if epicardial coronary artery diameter decreases by $>20 \%$ compared with baseline. If epicardial blood vessel narrowing greater than $25 \%$ is assessed along with ischemic changes on EKG, a diagnosis of epicardial coronary artery vasoconstriction is made. If the narrowing is less than $25 \%$ but associated with ischemic EKG, a diagnosis of coronary microvasculature vasospastic angina is made. If no coronary narrowing is noted with no ischemic changes, further testing with adenosine is performed to evaluate nonendothelial causes of micro-coronary vascular disease.

Intracoronary or intravenous adenosine is also used to measure the CFR. CFR measured during coronary angiography quantifies the CFV/CFR. Abnormal microcirculation is identified by administering adenosine during the angiogram ${ }^{[28]}$. CBF normally increases 2.5 to 5 times with adenosine compared to baseline. When there is an obstruction in the microcirculation, the CFR is reduced when measured with an intracoronary Doppler wire. Reis et al. ${ }^{[29]}$ suggested a CFV reserve threshold of 2.25 as an indicator of endothelium- 
independent coronary microvascular dysfunction with a sensitivity of $90 \%$ and specificity of $89 \%$. Currently, a CFR value of 2.5 is used as a convenient threshold. Patients with abnormal CFR are considered to have endothelium-independent microvascular angina ${ }^{[26]}$. According to Radico et al.$^{[30]}$, patients with CFR $>2.5$ after adenosine should be considered to have "true" cardiac syndrome X. Figure 2 elaborates the flow chart for evaluation of CMD. In addition to doppler, intracoronary CFR measurement of thermodilution has shown to be reliable and safe. A good correlation $(r=0.79, P<0.0001)$ has been demonstrated between Doppler and thermodilution derived $\mathrm{CFR}^{[31]}$.

\section{CONCLUSION}

CMD is suspected when a patient has typical anginal chest pain in the absence of obstructive lesion on coronary angiography. An accurate assessment of symptoms is warranted given the higher mortality and morbidity associated with CMD. The diagnosis of CMD can be aided solely by non-invasive testing. Cardiac MRI and PET enable us to identify coronary microvascular anatomy/physiology with high spatial resolution while avoiding the need for invasive studies. While the non-invasive modalities are yet to be standardized, future studies aimed at improving the diagnostic accuracy of non-invasive testing for CMD will enable accurate, prompt, and safe diagnosis.

\section{DECLARATIONS}

\section{Authors' contributions}

Made substantial contributions to the conception and design of the study and performed data analysis and interpretation: Voruganti D, Mehta JL

Performed data acquisition and provided administrative, technical, and material support: Voruganti D, Mehta JL

\section{Availability of data and materials}

Not applicable.

\section{Financial support and sponsorship}

None.

\section{Conflicts of interest}

Both authors declared that there are no conflicts of interest.

\section{Ethical approval and consent to participate}

Not applicable.

\section{Consent for publication}

Not applicable.

\section{Copyright}

(c) The Author(s) 2021.

\section{REFERENCES}

1. Godo S, Takahashi J, Yasuda S, Shimokawa H. Role of inflammation in coronary epicardial and microvascular dysfunction. Eur Cardiol 2021;16:e13. DOI PubMed PMC

2. Sinha A, Rahman H, Perera D. Coronary microvascular disease: current concepts of pathophysiology, diagnosis and management. Cardiovasc Endocrinol Metab 2020;10:22-30. DOI PubMed PMC

3. Recio-Mayoral A, Mason JC, Kaski JC, Rubens MB, Harari OA, Camici PG. Chronic inflammation and coronary microvascular dysfunction in patients without risk factors for coronary artery disease. Eur Heart J 2009;30:1837-43. DOI PubMed

4. Sara JD, Widmer RJ, Matsuzawa Y, Lennon RJ, Lerman LO, Lerman A. Prevalence of coronary microvascular dysfunction among patients with chest pain and nonobstructive coronary artery disease. JACC Cardiovasc Interv 2015;8:1445-53. DOI PubMed 
5. Pepine CJ, Ferdinand KC, Shaw LJ, et al; ACC CVD in Women Committee. Emergence of nonobstructive coronary artery disease: a woman's problem and need for change in definition on angiography. J Am Coll Cardiol 2015;66:1918-33. DOI PubMed PMC

6. Kaski J, Iqbal K. Cardiac syndrome X: pathogenesis and management. Heart Metab 2008;40:30-5.

7. Chen JW, Ting CT, Chen CI, et al. Coronary microvascular dysfunction is associated with ischemic-like electrocardiogram during exercise in patients with anginal chest pain and normal coronary angiograms. Jpn Heart J 1996;37:865-78. DOI PubMed

8. Hirano Y, Ozasa Y, Yamamoto T, et al. Hyperventilation and cold-pressor stress echocardiography for noninvasive diagnosis of coronary artery spasm. J Am Soc Echocardiogr 2001;14:626-33. DOI PubMed

9. Shimizu H, Lee JD, Yamamoto M, Satake K, et al. [Induction of coronary artery spasm by combined cold pressor and hyperventilation test in patients with variant angina]. J Cardiol 1994;24:257-61. (in Japanese). PubMed

10. Voci P, Testa G, Plaustro G. Imaging of the distal left anterior descending coronary artery by transthoracic color-Doppler echocardiography. Am J Cardiol 1998;81:74G-8G. DOI PubMed

11. Hozumi T, Yoshida K, Akasaka T, et al. Noninvasive assessment of coronary flow velocity and coronary flow velocity reserve in the left anterior descending coronary artery by Doppler echocardiography. J Am Coll Cardiol 1998;32:1251-9. DOI PubMed

12. Galiuto L, Sestito A, Barchetta S, et al. Noninvasive evaluation of flow reserve in the left anterior descending coronary artery in patients with cardiac syndrome X. Am J Cardiol 2007;99:1378-83. DOI PubMed

13. Sicari R, Rigo F, Cortigiani L, Gherardi S, Galderisi M, Picano E. Additive prognostic value of coronary flow reserve in patients with chest pain syndrome and normal or near-normal coronary arteries. Am J Cardiol 2009;103:626-31. DOI PubMed

14. Saraste M, Koskenvuo J, Knuuti J, et al. Coronary flow reserve: measurement with transthoracic Doppler echocardiography is reproducible and comparable with positron emission tomography. Clin Physiol 2001;21:114-22. DOI PubMed

15. Lethen H, P Tries H, Kersting S, Lambertz H. Validation of noninvasive assessment of coronary flow velocity reserve in the right coronary artery. A comparison of transthoracic echocardiographic results with intracoronary Doppler flow wire measurements. Eur Heart J 2003;24:1567-75. DOI PubMed

16. Rinkevich D, Belcik T, Gupta NC, Cannard E, Alkayed NJ, Kaul S. Coronary autoregulation is abnormal in syndrome X: insights using myocardial contrast echocardiography. J Am Soc Echocardiogr 2013;26:290-6. DOI PubMed PMC

17. Hulten E, Di Carli MF. FFRCT: solid PLATFORM or thin ice? J Am Coll Cardiol 2015;66:2324-8. DOI PubMed

18. Nishimiya K, Yin B, Piao Z, et al. Micro-optical coherence tomography for endothelial cell visualization in the coronary arteries. JACC Cardiovasc Imaging 2019;12:1878-80. DOI PubMed PMC

19. Thomson LE, Wei J, Agarwal M, et al. Cardiac magnetic resonance myocardial perfusion reserve index is reduced in women with coronary microvascular dysfunction. A National Heart, Lung, and Blood Institute-sponsored study from the Women's Ischemia Syndrome Evaluation. Circ Cardiovasc Imaging 2015;8:e02481. DOI PubMed PMC

20. Panting JR, Gatehouse PD, Yang GZ, et al. Abnormal subendocardial perfusion in cardiac syndrome X detected by cardiovascular magnetic resonance imaging. $N$ Engl J Med 2002;346:1948-53. DOI PubMed

21. Lanza GA, Buffon A, Sestito A, et al. Relation between stress-induced myocardial perfusion defects on cardiovascular magnetic resonance and coronary microvascular dysfunction in patients with cardiac syndrome X. J Am Coll Cardiol 2008;51:466-72. DOI PubMed

22. Murthy VL, Naya M, Taqueti VR, et al. Effects of sex on coronary microvascular dysfunction and cardiac outcomes. Circulation 2014;129:2518-27. DOI PubMed PMC

23. Wang X, Nie SP. The coronary slow flow phenomenon: characteristics, mechanisms and implications. Cardiovasc Diagn Ther 2011;1:37-43. DOI PubMed PMC

24. Moscarella E, Gragnano F, Cesaro A, et al. Coronary physiology assessment for the diagnosis and treatment of coronary artery disease. Cardiol Clin 2020;38:575-88. DOI PubMed

25. Cesaro A, Gragnano F, Di Girolamo D, et al. Functional assessment of coronary stenosis: an overview of available techniques. Is quantitative flow ratio a step to the future? Expert Rev Cardiovasc Ther 2018;16:951-62. DOI PubMed

26. Lee BK, Lim HS, Fearon WF, et al. Invasive evaluation of patients with angina in the absence of obstructive coronary artery disease. Circulation 2015;131:1054-60. DOI PubMed PMC

27. Ciliberti G, Seshasai SRK, Ambrosio G, Kaski JC. Safety of intracoronary provocative testing for the diagnosis of coronary artery spasm. Int J Cardiol 2017;244:77-83. DOI PubMed

28. Pepine CJ, Anderson RD, Sharaf BL, et al. Coronary microvascular reactivity to adenosine predicts adverse outcome in women evaluated for suspected ischemia results from the National Heart, Lung and Blood Institute WISE (Women's Ischemia Syndrome Evaluation) study. J Am Coll Cardiol 2010;55:2825-32. DOI PubMed PMC

29. Reis SE, Holubkov R, Lee JS, et al. Coronary flow velocity response to adenosine characterizes coronary microvascular function in women with chest pain and no obstructive coronary disease. J Am Coll Cardiol 1999;33:1469-75. DOI PubMed

30. Radico F, Cicchitti V, Zimarino M, De Caterina R. Angina pectoris and myocardial ischemia in the absence of obstructive coronary artery disease: practical considerations for diagnostic tests. JACC Cardiovasc Interv 2014;7:453-63. DOI PubMed

31. Barbato E, Aarnoudse W, Aengevaeren WR, et al; Week 25 study group. Validation of coronary flow reserve measurements by thermodilution in clinical practice. Eur Heart J 2004;25:219-23. DOI PubMed 